\title{
Actinomycosis Simulating Malignant Large Bowel Obstruction
}

\author{
José Augusto Ferreira Bittencourt, Elmes Luiz Andreis, \\ Eduardo Lahude Lima, Dalvani Elias Dorn and Virgínia Muller
}

Surgery Department of Nossa Senhora da Conceição

Hospital, Porto Alegre, RS, Brazil

\begin{abstract}
We present a case of a 58 year old white male who entered the hospital with abdominal pain and developed large bowel obstruction, simulating malignant disease. Anatomopathological examination showed abdominal actinomycosis, a rare presentation of this disease. Key Words: Actinomycosis, abdominal, bowel obstruction.
\end{abstract}

Actinomycosis is a chronic suppurative granulomatous disease caused mainly by Actinomyces israelli [1]. This bacterium is universally distributed and is not very virulent; it is rarely related to abdominal disease. Primary bowel involvement is rare, but it has increased in frequency over the last few years [2-8]. Since it is difficult to diagnose, and presents an unspecific clinical picture, this disease is generally only found during postoperative anatomopathological examination, and it is confused with other abdominal diseases, such as diverticulitis, abscesses, inflammatory bowel disease and carcinoma [4,6-12]. We report a case of bowel obstruction due to actinomycosis, simulating neoplastic disease.

\section{Case Report}

A Caucasian male, 58 years old, visited the emergency room at Hospital Nossa Senhora da Conceição, with a complaint of abdominal pain and distension. Previously healthy, he reported a history of episodes of very intense diffuse abdominal pain, accompanied by distension and vomiting, which had

Received on 05 August 2003; revised 12 January 2004.

Address for correspondence: Dr. José Augusto Ferreira Bittencourt - Rua Corte Real 405 ap04 Porto Alegre RS Zip code: 90630-080. E-mail: drbittencourt@yahoo.com.br Phone number: 051 96531021/05130232194.

The Brazilian Journal of Infectious Diseases 2004;8(2):186-189 (C) 2004 by The Brazilian Journal of Infectious Diseases and Contexto Publishing. All rights reserved. developed over 10 months and resolved spontaneously. He told of alternating episodes of constipation and diarrhea between the crises. During this period he had lost $10 \mathrm{~kg}$. He denied having had previous surgery. On examination he presented discrete abdominal distention and an absence of palpable masses. The laboratory tests were normal, including a negative HIV serum test. A simple abdominal $\mathrm{X}$-ray did not show any significant changes. He was given a barium enema, which did not present any abnormalities. He was then evaluated by examination of bowel transit, which showed marked distention of small bowel loops, with a possible mechanical obstruction of the middle and distal portions of the ileum. After this study, the abdominal pain and distension became markedly worse and the patient was submitted to an emergency laparotomy, due to an intestinal occlusion, suggesting a neoplasm.

At abdominal exploration, an intense inflammatory process was found involving the cecum and distal ileum. There were multiple firm fibrotic adhesions of the loops, and the cecal appendix could not be identified. The macroscopic aspect of the lesion was strongly suggestive of neoplasm. Thus, it was decided to perform an ileocolectomy, with primary anastomosis.

The patient had a satisfactory postoperative evolution. The anatomopathological examination showed chronic and acute suppurative inflammation in the mesentery and mesocolon, multiple adhesions of the small and large bowel, and a large number of abscesses, with the presence of sulfurous granules, strongly indicative of intestinal actinomycosis (Figure 1-3). Penicillin was given I.V. and the patient was 
Figure 1. Distal ileum and ascending colon: macroscopic appearance

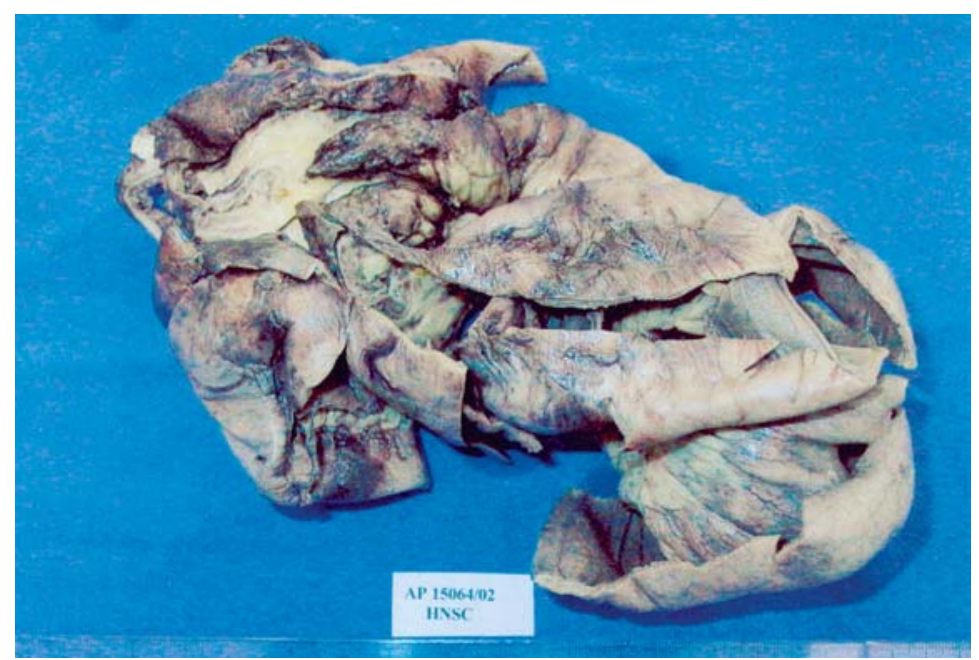

Figure 2. Actiomycotic abcess: macroscopic appearance

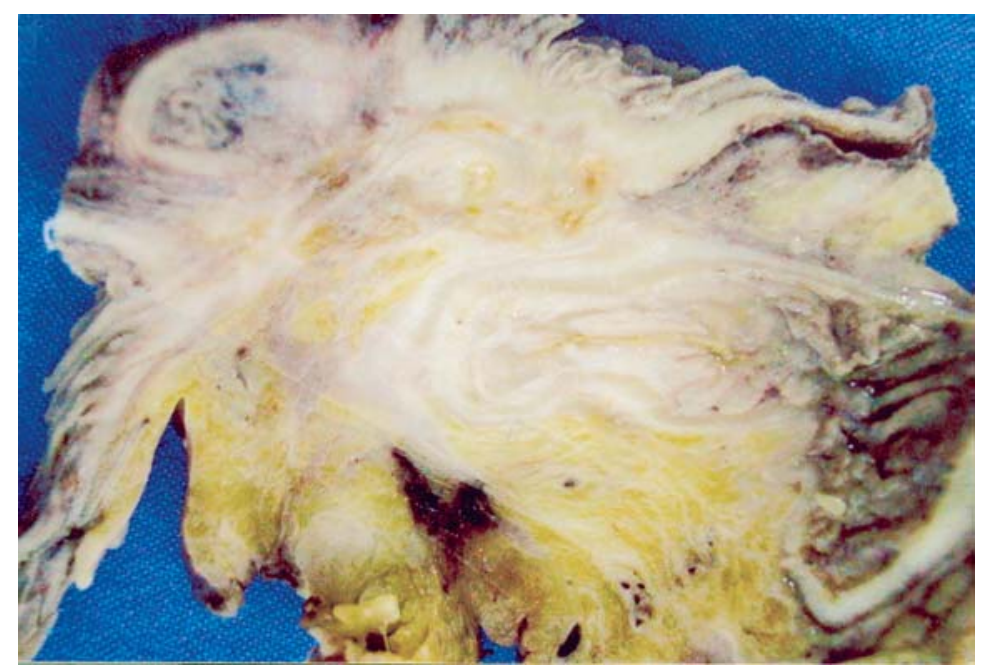

Figure 3. Sulfurous granules with a neutrocytic reaction under microscopy

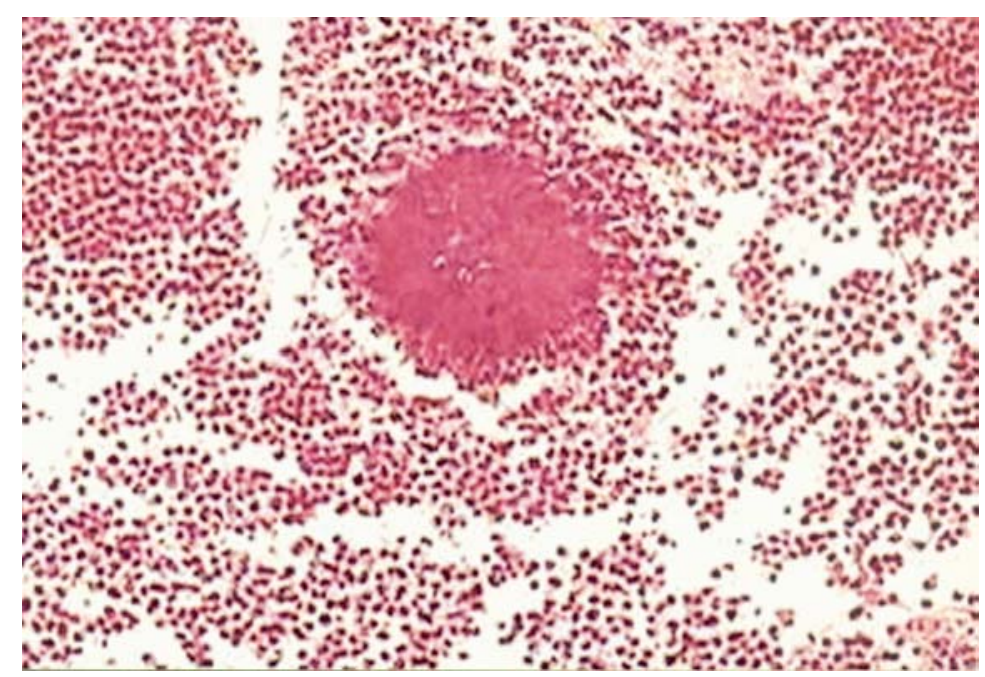

www.bjid.com.br 
discharged on the $14^{\text {th }}$ day after surgery, with complementary treatment using oral antibiotics for six months.

\section{Discussion}

Actinomycosis is a rare infectious disease caused in almost all cases by a filamentous anaerobic grampositive bacterium called Actinomyces israelli. This microorganism is not very virulent, and it is usually found in the human oropharynx, especially in individuals with bad oral hygiene [1]. This bacterium is widely distributed, with equal urban and rural distribution, and it is three times more frequent in men [13]. When it is pathogenic, it cause a characteristic granulomatous inflammatory reaction, followed by necrosis and extensive fibrotic reaction. It mainly presents in three forms: cervicofacial (50\%), abdominal (20\%) and thoracic $(15 \%)[6,7,14,15]$. The involvement of the gynecological tract has been recently reported, related to the use of an intrauterine device $[6,14]$. Hydronephrosis due to extrinsic compression of the actinomycotic granuloma has also been reported $[6,7,11]$. Anorectal and hepatobiliary primary actinomycosis have already been described in the literature (16-18). The involvement of multiple organs, such as in this patient, is rare but has been previously reported $[6,7,19]$.

Intestinal actinomycosis involves the cecal appendix and terminal ileum in $65 \%$ of cases. The symptoms are unspecific and include a high temperature, loss of weight, constipation and abdominal pain [6,7]. Predisposing factors include previous abdominal surgeries, foreign bodies, appendicitis, bowel perforations or neoplasm. Diagnosis is extremely difficult, and it is made preoperatively in only $10 \%$ of the cases [7]. Although this bacterium is opportunistic, it has rarely been associated with HIV [3].

The presence of sulfur granules occurs in $50 \%$ of the cases and may often be observed with the naked eye. Although they strongly suggest a diagnosis, they are not pathognomonic for the disease $[6,7,13]$.
Bacterial culture supplies a definitive diagnosis, but often there are false-negative results $[6,9,13,19]$. Imaging studies are not very useful for diagnosis, though computed tomography is the examination that supplies the best information. Colonoscopy may suggest a benign process and should be performed whenever possible [6].

Bowel obstruction due to actinomycosis is very rare, and few cases have been reported [6,10,20,21]. Treatment with penicillin alone for 2 to 6 months is effective in $90 \%$ of the cases. Erythromycin and tetracycline are adequate alternatives. Surgery is needed only for cases of bowel obstruction or difficulty in ruling out neoplastic disease, as well as an adjuvant in debridement of necrotic tissues and abscesses, although it is performed in most cases due to the difficulty in recognizing the disease $[6,7,11,19]$.

Intestinal actinomycosis is an unusual disease that must be considered in the differential diagnosis of abdominal masses. It is difficult to diagnose, but diagnosis is the key to treatment. Surgery should be avoided due to the adequacy of clinical treatment. It should be reserved for the complicated cases, such as obstructive or undifferentiated pictures of cancer. The lack of precise diagnostic methods makes diagnosis and management by the surgeon difficult, complicated by the fact that this is a rare disease.

\section{References}

1. Tedder M., Wolfe W.G. Actinomycosis and nocardial infections. Chest Surg North Am 1993;3:653-70.

2. Wohlgemuth S.D., Gaddy M.C. Surgical implications of actinomycosis. South Med J 1986;79:1574-8.

3. Smith T.R. Actinomycosis of the distal colon and rectum. Gastrointest Radiol 1992;17:274-6.

4. Thompson J.R., Watts R., Thompson W.C. Actinomycetoma masquerading as an abdominal neoplasm. Dis Colon Rectum 1982;25:368-70.

5. Samuel I., Dixon M.F., Benson E.A. Actinomysis complicating chronic diverticulitis of the sigmoid colon: A missed association. Postgrad Med J 1992;68:57-8.

6. Yeguez J.F., Martinez S., Sands L.R., Hellinger M.D. Pelvic actinomycosis as malignant large bowel obstruction: A case report and a review of the literature. Am Surg 2000;66(1):85-90. 
7. Cintron J.R., Del Pino A., Duarte B., Wood D. Abdominal actinomycosis. Dis Colon Rectum 1996;39(1):105-8.

8. Weese W.C., Smith I.m. A study of 57 cases of actinomycosis over a 36-year period: a diagnostic failure with good prognosis after treatment. Arch Int Med 1975; 135 : $1562-8$.

9. Waaddegaard P., Dzleglel M. Actinomycosis mimicking abdominal neoplasm: Case report. Acta Chir Scand 1988; $154: 315-6$.

10. Hinnie J., Jaques B.C., Bell E., et al. Actinomycosis presenting as carcinoma. Postgrad Med J 1995;71:749-50.

11. Bertram P., Treutner K., Kleinschimidt L., et al. Rectal stricture caused by actinomycosis of the pelvis. Eur $\mathbf{J}$ Surg 1996;162:837-9.

12. Chica F.S., Ferrer F.V., Del Pozo C.D., et al. Abdominal actinomycosis simulating crohn's disease. Gastroenterol Hepatol 2001;24(6):300-2.

13. Brown J. Human actinomycosis: a study of 181 subjects. Human Pathol 1973;4:319-30.

14. O'Connor K.F., Bagg M.N., Croley M.R. Pelvic actinomycosis associated with intrauterine devices. Radiology 1989; 170:559-60.

15. Endo S., Murayama F., Yamaguchi T., et al. Surgical considerations for pulmonary actinomycosis. Ann Thorac Surg 2002;74:185-90.

16. Brewer N.S., Spencer R.J., Nichols D.R. Primary anorectal actinomycosis. JAMA 1974;228:1397-2000.

17. Ormsby A.H., Bauer T.W., Halls G.S. Actinomycosis of the cholecystic duct: Case report and a review. Pathology 1998;30:65-7.

18. Alvardo-Cerna R., Bracho-Riqueline R. Actinomycosis a complication of a fistula-in-ano: Report of case. Dis Colon Rectum 1994;37:378-80.

19. Deshmukh N., Heaney S.J. Actinomycosis at multiple colonic sites. Am J Gastroenterol 1986;81:1212-4.

20. Kaya E., Yilmazlur T., Emiroglu Z., et al. Colonic actinomycosis: Report of a case and review of the literature. Surg Today 1995;25:923-6.

21. Uchiyama N., Ishikawa T., Miyakawa K., et al. Abdominal actinomycosis: Barium enema and computed tomography. J Gastroenterol 1997;32:89-94. 